\title{
Pretreatment with DNA-damaging agents permits selective killing of checkpoint-deficient cells by microtubule-active drugs
}

\author{
Mikhail V. Blagosklonny, Robert Robey, Susan Bates, and Tito Fojo \\ Medicine Branch, National Cancer Institute, National Institutes of Health, Bethesda, Maryland 20892, USA \\ Address correspondence to: Mikhail V. Blagosklonny, Medicine Branch, Building 10, R 12N226, National Institutes of \\ Health, Bethesda, Maryland 20892, USA. Phone: (301) 496-6313; Fax: (301) 402-0172; E-mail: mikhailb@box-m.nih.gov.
}

Received for publication October 6, 1999, and accepted in revised form January 12, 2000.

Cell-cycle checkpoint mechanisms, including the p53- and p21-dependent $\mathrm{G}_{2}$ arrest that follows DNA damage, are often lost during tumorigenesis. We have exploited the ability of DNA-damaging drugs to elicit this checkpoint, and we show here that such treatment allows microtubule drugs, which cause cell death secondary to mitotic arrest, to kill checkpoint-deficient tumor cells while sparing checkpoint-competent cells. Low doses of the DNA-damaging drug doxorubicin cause predominantly $\mathrm{G}_{2}$ arrest without killing HCT116 cells that harbor wt p53. Doxorubicin treatment prevented mitotic arrest, Bcl-2 phosphorylation, and cell death caused by paclitaxel, epothilones, and vinblastine. In contrast, doxorubicin enhanced cytotoxicity of FR901228, an agent that does not affect microtubules. Low doses of doxorubicin did not arrest p21-deficient clones of HCT116 cells and did not protect these cells from cytotoxicity caused by microtubule drugs, but cells in which $\mathrm{p} 21$ expression was restored enjoyed partial protection under these conditions. Moreover, in p53-deficient clones of HCT116 cells doxorubicin did not induce either p53 or $\mathrm{p} 21$ and provided no protection against paclitaxel-induced cytotoxicity. Therefore, (a) p53dependent $\mathrm{p} 21$ induction caused by doxorubicin protects from microtubule drug-induced cytotoxicity, and (b) pretreatment with cytostatic doses of DNA-damaging drugs before treatment with microtubule drugs results in selective cytotoxicity to cancer cells with defective $\mathrm{p} 53 / \mathrm{p} 21$ dependent checkpoint.

J. Clin. Invest. 105:533-539 (2000).

\section{Introduction}

Microtubule-active and DNA-damaging drugs are widely used in the treatment of cancer $(1,2)$, but toxicity to normal cells limits the benefits of chemotherapy. DNA damage causes accumulation of wt p53 protein (3), which in turn transcriptionally induces $\mathrm{P} 21^{\mathrm{WAF} 1 / \mathrm{CIP} 1}(4)$ and inhibits cell-cycle progression at $\mathrm{G}_{1}$ and $\mathrm{G}_{2}$ phases (5-8). Loss of wt p53 function is the most common genetic alteration in cancer (9-11). In thymocytes and E1A-transformed fibroblasts, wt p53 is required for apoptosis caused by DNA damage $(12,13)$. In human cancer cells, the relationship between loss of $\mathrm{p} 53$ and drug sensitivity is more complex (14), but inactivation of p53 often correlates with resistance to DNA-damaging drugs (15-17). Although viewed as an unfavorable event, inactivation of p53 could be elegantly exploited for therapeutic advantage (18). Here we propose an alternative approach.

As demonstrated by Bunz et al., lack of wt p53 or its transcriptional target, p21, allows cells to enter mitosis after DNA damage, whereas cells with wt p53 are arrested at the $\mathrm{G}_{2}$ phase (19). We envisioned that this seemingly slight difference could be exploited to achieve a selective response to microtubule-active drugs such as paclitaxel, epothilones, and vinca alkaloids. Micro- tubule drugs interfere with the assembly of the mitotic spindle and arrest cells in mitosis, ultimately causing cell death (20-22).

Here we show that cytostatic doses of DNA-damaging drugs transform toxic mitotic arrest caused by microtubule-active drug to nontoxic $\mathrm{G} 2$ arrest, thus abrogating cell death. This protection requires an intact p53/p21 pathway and consequently can be exploited for selective killing of cancer cells lacking normal $\mathrm{G}_{2}$ checkpoint.

\section{Methods}

Cell lines. The human colon cancer cell line HCT116, and 2 clones lacking p21 (p21-/), S4 and S14, generated from HCT116 cells (7) were a gift from B. Vogelstein (John Hopkins University, Baltimore, Maryland, USA). The clone lacking p53 (p53-/-) generated from HCT116 cells (14) was a gift from B. Vogelstein. HPV-E6-expressing clones of HCT116 cells, HCT-E6, were a gift from W.S. El-Deiry (University of Pennsylvania, Philadelphia, Pennsylvania, USA) and have been described previously (23). Parental HCT116 colon cancer cells are characterized by normal p53/p21 checkpoint. Cells lacking p53 and p21 fail to be arrested in the $\mathrm{G} 2$ phase after radiation, enter mitosis, and undergo endoreplication $(14,19)$. 
Reagents. Reagents used were paclitaxel (Taxol; Bristol-Myers, Princeton, New Jersey, USA) with a stock solution of $6 \mathrm{mg} / \mathrm{mL}$; vincristine and vinblastine (Eli Lilly Co., Indianapolis, Indiana, USA) with a stock solution of $1 \mathrm{mg} / \mathrm{mL}$, or were obtained from Sigma Chemical Co. (St. Louis, Missouri, USA) and dissolved in ethanol at $1 \mathrm{mg} / \mathrm{mL}$. Epothilones A and B were provided by F. Lee (Bristol-Myers) and dissolved in water. Adriamycin was obtained from Sigma Chemical Co. and dissolved in DMSO as a $2 \mathrm{mg} / \mathrm{mL}$ stock solution. FR901228 (depsipeptide) was obtained from Chemistry and Synthesis Branch (National Cancer Institute, National Institutes of Health, Bethesda, Maryland, USA) and prepared as a $1 \mathrm{mg} / \mathrm{mL}$ stock solution in water.

p53 and p21 expression vectors. Ad-p53, a wt p53-expressing replication-deficient adenovirus, and Ad-LacZ, a $\beta$-galactosidase-expressing replication-deficient adenovirus were obtained from $B$. Vogelstein. Ad-p21, a wt p21-expressing adenovirus was obtained from W.S. El-Deiry, and viral titer was determined as described previously (23).

Western blot analysis. Proteins were harvested in TNESVF buffer (50 mM Tris $\mathrm{HCl}[\mathrm{pH}$ 7.5], $2 \mathrm{mM}$ EDTA, $100 \mathrm{mM} \mathrm{NaCl}, 1 \mathrm{mM}$ sodium ortovanadate, sodium fluoride, $1 \% \mathrm{NP}-40$ ) with protease inhibitors and were resolved on $12.5 \%$ for $\mathrm{p} 21^{\mathrm{WAF} 1 / \mathrm{CIP} 1}$ or $\mathrm{Bcl}-2$, and on $7.5 \%$ SDS-PAGE for Raf-1, p120, mdm-2 and p53 detection as described previously (23). If indicated, proteins were resolved on NuPAGE 4-12\% BisTris gel with MOPS running buffer (NOVEX, San Diego, California, USA) according to manufacturer's instructions. Immunoblot was performed using the following antibodies: antihuman monoclonal WAF1 (EA10), p53 (PAb2) and mdm-2 antibodies (Oncogene Research Products, Cambridge, Massachusetts, USA) anti-Raf-1 rabbit polyclonal (C12; Santa Cruz Biotechnology Inc., Santa Cruz, California, USA), and antihuman Bcl-2 monoclonal (DAKO Corp., Carpinteria, California, USA) antibodies.

MTT assay. A total of 2000 cells were plated in 96well flat-bottom plates in $100 \mu \mathrm{L}$ of medium. The next day, cells were exposed to the pharmacological agents. After 2 days of the last drug addition, $20 \mu \mathrm{L}$ of $5 \mathrm{mg} / \mathrm{mL}$ MTT solution in PBS was added to each well for 4 hours. The medium was discarded, and $170 \mu \mathrm{L}$ DMSO was added to each well to dissolve the formazan crystals. The absorbance at $540 \mathrm{~nm}$ was determined using a Biokinetics plate reader (Bio-Tek Instruments Inc., Winooski, Vermont, USA). Triplicate wells were assayed for each condition, and standard deviations were determined. $\mathbf{a}$

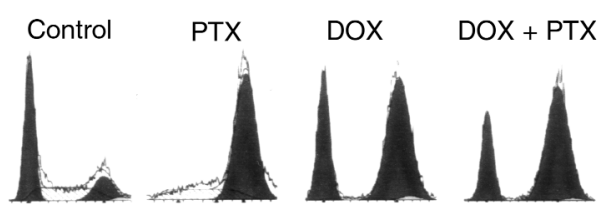

b

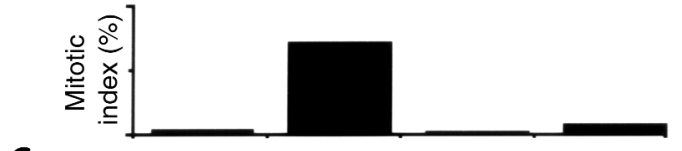

C
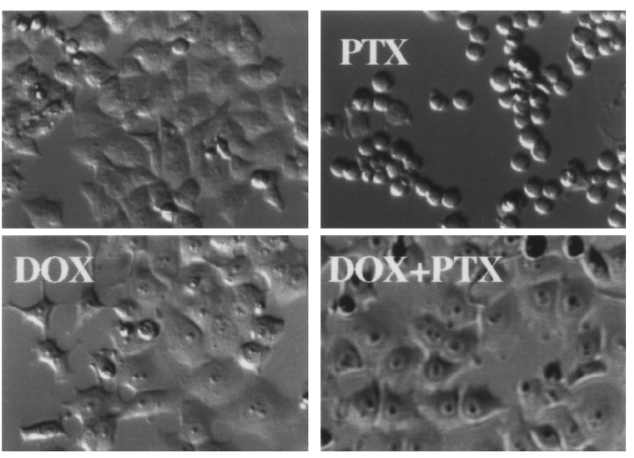

d $\mathrm{Bcl}-2$

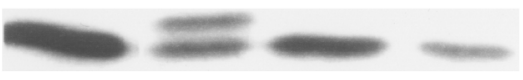

e

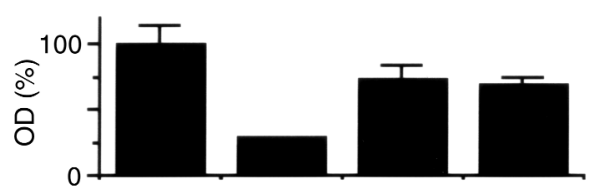

f

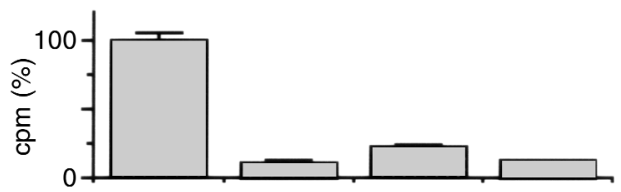

g

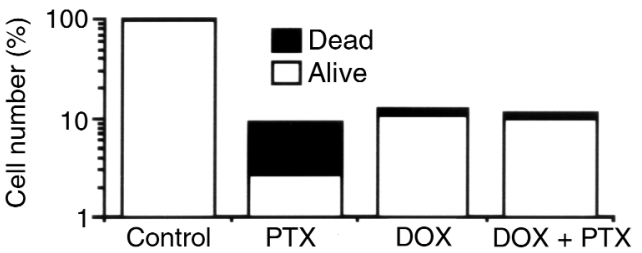

Figure 1

Doxorubicin-induced $\mathrm{G}_{2}$ arrest versus paclitaxel-induced mitotic arrest, $\mathrm{Bcl}-2$ phosphorylation and cell death. $\mathrm{HCT} 116$ cells were incubated with $100 \mathrm{ng} / \mathrm{mL}$ doxorubicin (DOX) or left untreated. After 12-16 hours, $100 \mathrm{ng} / \mathrm{mL}$ paclitaxel (PTX) was added, if indicated. Pretreated cells continued in doxorubicin until harvest. (a) Cell-cycle distribution measured by FACS analysis was performed 24 hours after the addition of PTX. (b) Mitotic index was measured by DAPI staining after 24 hours after the addition of PTX. (c) Cells, treated as indicated, were photographed 16 hours after the addition of PTX. (d) Bcl-2 protein phosphorylation was demonstrated by immunoblot 12 hours after the addition of PTX. (e) Number of live cells, as measured by MTT assay, 2 days after the addition of PTX. (f) DNA replication, as measured by [ $\left.{ }^{3} \mathrm{H}\right]$ thymidine incorporation, 16 hours after the addition of PTX. (g) The number of dead and live cells was counted with trypan blue staining 3 days after the addition of PTX. Open bars represent live cells (excluded trypan blue); filled bars represent dead cells (stained with trypan blue). 
Mitotic index. Cells were centrifuged, fixed, and stained with DAPI. For each sample, 100-500 cells were randomly counted by microscopy, and mitotic cells were scored by their lack of nuclear membrane and evidence of chromosome condensation.

DNA synthesis. DNA synthesis was monitored by $\left[{ }^{3} \mathrm{H}\right]$ thymidine incorporation. In brief, 2,000 cells were plated in 96-well flat-bottom plates, or 15, 000 cells were plated in 24-well plates. The next day, cells were treated with drugs. At the indicated time, cells were incubated with $1 \mu \mathrm{Ci}\left[\right.$ methyl ${ }^{3} \mathrm{H}$ ] thymidine (Amersham Pharmacia Biotech Inc., Piscataway, New Jersey, USA) for an additional 4-8 hours, and then acid-insoluble radioactivity was determined.

Number of dead and alive cells. A total of 25, 000 cells were plated in 24-well plates in $1 \mathrm{~mL}$ of medium. The next day, cells were treated with the drugs. After 3-4 days, cells were trypsinized and each condition was counted in triplicate on a Coulter Z1 cell counter (Coulter Electronics Ltd., Hialeah, Florida, USA). In addition, cells were incubated with trypan blue, and the number of blue (dead) cells and transparent (live) cells was counted by microscopy.

Cell-cycle analysis. Cells were harvested by trypsinization, washed with PBS, resuspended in $75 \%$ ethanol in PBS, and kept at $40^{\circ} \mathrm{C}$ for at least 30 minutes. Before analysis, cells were washed again with PBS and resuspended and then incubated for 30 minutes in propidium iodide staining solution containing $0.05 \mathrm{mg} / \mathrm{mL}$ propidium iodide (Sigma Chemical Co.), $1 \mathrm{mM}$ EDTA, $0.1 \%$ Triton-X-100, and $1 \mathrm{mg} / \mathrm{mL}$ RNAse A in PBS. The suspension was then passed through a nylon mesh filter and analyzed on a Becton Dickinson FACScan (Franklin Lakes, New Jersey, USA).

\section{Results}

Lack of paclitaxel effects in doxorubicin-arrested HCT116 cells. Exposure of HCT116 cells to either microtubule drugs such as paclitaxel (PTX) or to low doses of DNA-damaging drugs such as $50-100 \mathrm{ng} / \mathrm{mL}$ doxorubicin (DOX) causes accumulation of cells predominantly in $G_{2} / M$ phase. In addition to $G_{2} / M$ arrest, doxorubicin causes $\mathrm{G}_{1}$ arrest (Figure 1a). Cells pretreated with $100 \mathrm{ng} / \mathrm{mL}$ doxorubicin for 12 hours and then treated with $100 \mathrm{ng} / \mathrm{mL}$ PTX for an additional 16 hours had essentially the same cell-cycle distribution as did cells treated with doxorubicin alone (Figure 1a). Although both $\mathrm{G}_{2}$ and mitotic arrest are included in the $\mathrm{G} 2 / \mathrm{M}$ peak and thus are indistinguishable on cytometry (Figure 1a), they can be easily distinguished by mitotic index (Figure 1b). Thus, although the $\mathrm{G}_{2} / \mathrm{M}$ arrest by paclitaxel was exclusively mitotic, the $\mathrm{G}_{2} / \mathrm{M}$ arrest by doxorubicin was exclusively $\mathrm{G}_{2}$. Pretreatment with doxorubicin prevented mitotic arrest caused by PTX (Figure 1, b and c). Mitotic arrest coincides with the appearance of round cells (Figure 1c, PTX) and culminates in cell death within 2 days. Pretreatment with doxorubicin completely prevented the effects of paclitaxel on morphology (Figure 1c, DOX + PTX versus PTX).

Mitotic arrest caused by paclitaxel is associated with phosphorylation of proteins on multiple serine residues (22) with characteristic mobility shift such as shown for Bcl-2 protein (Figure 1d). Doxorubicinpretreatment abrogated this early marker of the paclitaxel-induced cytotoxicity (Figure 1d), determining different cell fate. Although cell viability dropped after paclitaxel treatment, pretreatment with doxorubicin prevented this decline (Figure 1e). Cytostatic doses of another DNA-damaging drug, a

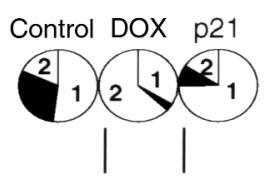

b

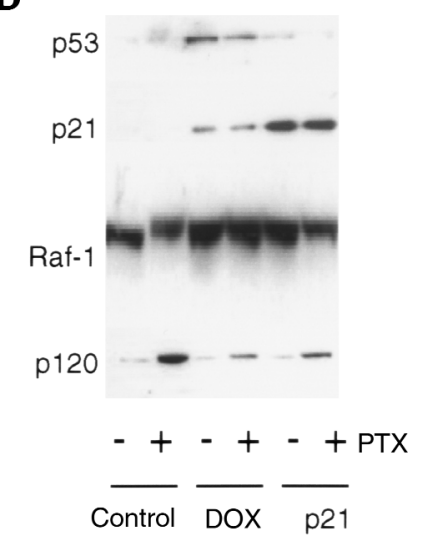

c

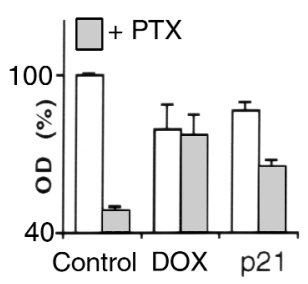

Figure 2

Comparison of DOX- and p21-mediated cytoprotection. (a) HCT116 cells were treated with $100 \mathrm{ng} / \mathrm{mL}$ doxorubicin (DOX) or infected with 10 moi Ad-p21 (p21) for 36 hours, and then cell-cycle analysis was performed as described in Methods. The pie chart represents the percent of cells in each phase of the cell cycle: 1 = G1 phase; 2 = G2 phase; solid area = S phase. Control adenovirus, Ad-LacZ, did not change cell-cycle distribution. (b) HCT116 cells were pretreated with $100 \mathrm{ng} / \mathrm{mL}$ DOX for 16 hours or 10 moi Ad-p21 (p21) for 24 hours. A plus sign indicates that cells were treated with $100 \mathrm{ng} / \mathrm{mL}$ PTX for 20 hours; a minus sign indicates that they were left untreated. Cells were lysed after 20 hours, and p53, p21, Raf-1, and p120 were measured by immunoblot. (c) HCT116 cells were pretreated as already described here and then treated with $100 \mathrm{ng} / \mathrm{mL}$ PTX. After 48 hours the MTT assay was performed. 
Figure 3

Doxorubicin does not protect $\mathrm{p} 21^{-/-}$cells. (a) HCT116 and $\mathrm{p} 21^{-/-}$cells were incubated with $100 \mathrm{ng} / \mathrm{mL}$ doxorubicin for 24 hours and then assayed for mdm-2 and $\mathrm{p} 21$ proteins by immunoblot analysis. (b) HCT116 and p 21-/cells were incubated with the indicated concentrations of doxorubicin for 24 hours, and then $\left[{ }^{3} \mathrm{H}\right]$ thymidine incorporation was measured. (c and d) HCT116 (c) and p21/- cells (d) were pretreated with indicated dose of doxorubicin for 12 hours, and then cells were treated with $100 \mathrm{ng} / \mathrm{mL}$ PTX (gray bars) or left untreated (open bars). MTT test was performed after 2 days. a

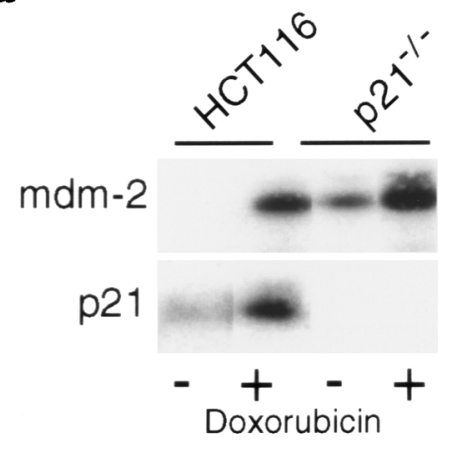

b

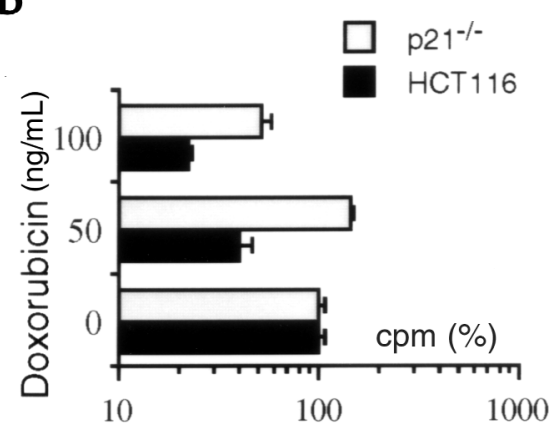

C

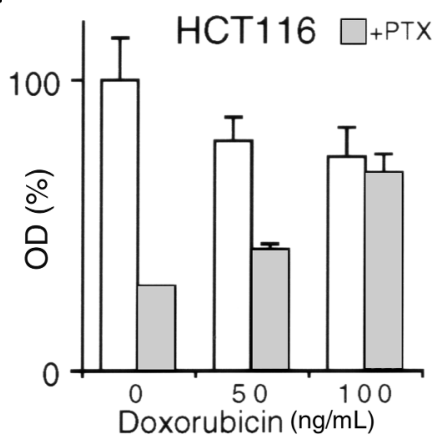

d

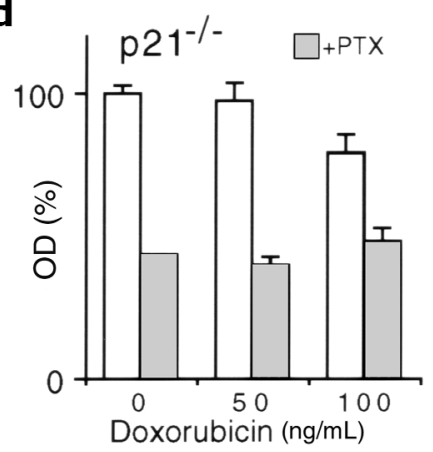

etoposide, were also cytoprotective against paclitaxel (data not shown). [ $\left.{ }^{3} \mathrm{H}\right]$ Thymidine incorporation was decreased by either paclitaxel or doxorubicin, and, as expected, pretreatment with doxorubicin could not restore $\left[{ }^{3} \mathrm{H}\right]$ thymidine incorporation (Figure 1f). A decrease in the number of dead cells was the most sensitive test to determine cytoprotection after 3 days (Figure $1 \mathrm{~g}$ ). Also, minimal cell death was observed in doxorubicin-pretreated cells even after 7 days (data not shown).

p21 overexpression is partially protective against paclitaxel in HCT116 cells. Previous studies have shown that p53-dependent p21 induction is required for $G_{1}$ and $\mathrm{G}_{2}$ arrests after DNA damage $(7,8,19)$. Consequently, we examined the ability of a p21-expressing adenovirus (Ad-p21) to protect from paclitaxel cytotoxicity. Treatment with doxorubicin and overexpression of p21-arrested cells with different proportion of the phases $G_{1}$ or $G_{2}$ arrests. Although doxorubicin caused predominantly $\mathrm{G}_{2}$ arrest, overexpression of exogenous p 21 caused predominantly $\mathrm{G}_{1}$ arrest in HCT116 cells (Figure 2a). A proportion of cells that arrested at $G_{1}$ or $G_{2}$ after DNA damage depends on cell type and the levels of p53/p21 induction $(19,24)$. Doxorubicin induced both p53 and p21, whereas infection with Ad-p21 increased p21 only (Figure $2 b$ ). The level of p21 in the Ad-p21-infected cells was sub-

\section{Figure 4}

Comparison of PTX with other microtubule-active drugs. HCT116 cells (a) or p $21^{-/-}$cells (b) were pretreated with $100 \mathrm{ng} / \mathrm{mL}$ doxorubicin or left without pretreatment. After 16 hours, cells were treated with $100 \mathrm{ng} / \mathrm{mL}$ of indicated drug. MTT assay was performed after 2 days. Results represent percent of untreated cells or DOX-pretreated cells, respectively. Epo, epothilone. VBL, vinblastine. stantially higher than in doxorubicin-treated cells. The differences in cell-cycle distribution between doxorubicin-treated cells and those infected with Adp21 may be explained by differences in the levels of p21, with higher levels resulting in $G_{1}$ instead of $G_{2}$ arrest in HCT116 cells. Furthermore, wt p53 induced by doxorubicin can activate other targets that participate in the $\mathrm{G}_{2}$ checkpoint $(25,26)$. Regardless of the distribution in $G_{1}$ versus $G_{2}$, overexpression of p21 


\section{Figure 5}

Protection by $\mathrm{p} 21$ against PTX in $\mathrm{p} 21^{-/-}$. (a) Cells were infected with 10 moi Ad-p21, and after 24 hours, treated with $100 \mathrm{ng} / \mathrm{mL}$ PTX for 20 hours as indicated. Cells were lysed, and immunoblot for p53 and p21 was performed. (b) Cells were infected with 10 moi Ad-p21, and after 24 hours, cell-cycle analysis was performed. No doxorubicin or paclitaxel was added in this experiment. (c). Cells were infected with 10 moi Ad-p21, and after 24 hours, treated with $100 \mathrm{ng} / \mathrm{mL}$ PTX as indicated. MTT assays were performed after 2 days. a

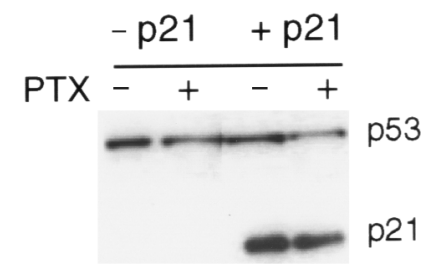

b

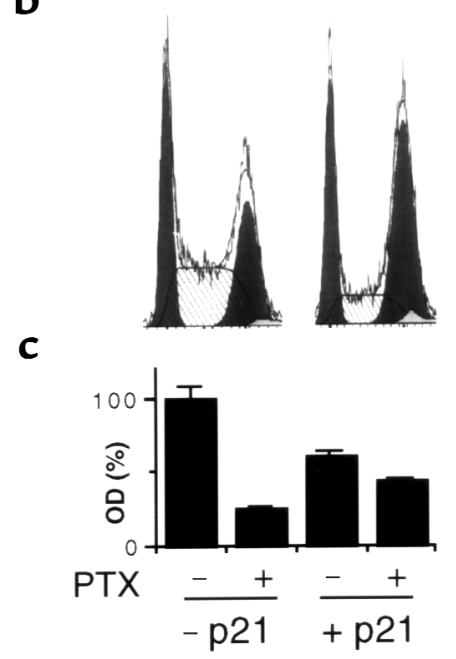

induced $\mathrm{p} 120$ protein accumulation. However, infection with Ad-p21 was less effective than doxorubicin in preventing cell death, as measured after 48 hours of exposure to paclitaxel (Figure 2c). This difference can be explained by the fact that doxorubicin completely arrested cells, whereas alone, p21 cannot completely sustain cell-cycle arrest and, over time, allows cells to enter mitosis.

Doxorubicin is not protective in cells lacking $p 21$. To elucidate further the role of $\mathrm{p} 21$, we utilized HCT 116 cells lacking p21 (p21-/- cells) which, as previously shown, do not undergo $G_{1}$ or $G_{2}$ growth arrest after radiation $(7,19)$. As expected, doxorubicin induced both $\mathrm{Mdm}-2$ and $\mathrm{p} 21$, p53-responsive proteins, in HCT116 cells, whereas it induced $\mathrm{mdm}-2$ but not $\mathrm{p} 21$ in $\mathrm{p} 21^{-/}$ cells (Figure 3a). Doxorubicin inhibited $\left[{ }^{3} \mathrm{H}\right]$ thymidine incorporation in parental cells, but this was less pronounced in $\mathrm{p} 21^{-/-}$cells (Figure $3 b$ ). In contrast to parental cells, $\mathrm{p} 21^{-/-}$cells were not protected against paclitaxel-induced cytotoxicity (Figure 3, c and d). It is important to emphasize that doses above $100 \mathrm{ng} / \mathrm{mL}$ were toxic to both $\mathrm{p} 21^{-/-}$and parental cells. In agreement with previous reports $(8,19)$, p21-deficient

partially abrogated early events associated with paclitaxel-induced mitotic arrest and cytotoxicity (Figure $2 b)$. Hyperphosphorylation of Raf- 1 protein, a marker of mitotic arrest of microtubule drugs, was diminished not only by doxorubicin but also by p21 (Figure $2 \mathrm{~b}$ ). Accumulation of the 120 nucleolar protein, a sensitive marker of the drug-induced cytotoxicity (27), was dramatically induced by paclitaxel (Figure $2 \mathrm{~b}$, lane 1 versus lane 2 ). In contrast to cytotoxic doses, cytostatic doses of doxorubicin do not affect p120 protein levels (27), and as shown in Figure 2b, both doxorubicin and Ad-p21 abrogated paclitaxel-

a

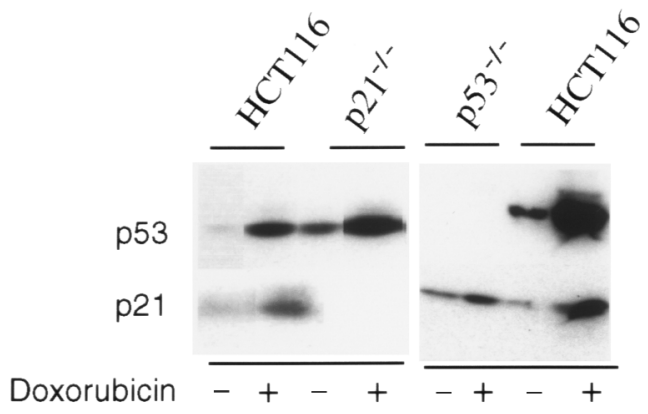

Figure 6

Doxorubicin fails to protect p53-/- cells. (a) Effects of doxorubicin on $\mathrm{p} 53$ and $\mathrm{p} 21$ proteins in HCT116, $\mathrm{p} 21^{-/-}$, and p $53^{-/-}$cells. Cells were incubated with (+) or without (-) $100 \mathrm{ng} / \mathrm{mL}$ doxorubicin for 16 hours and then assayed by immunoblot analysis. (b) Cells were pretreated with $100 \mathrm{ng} / \mathrm{mL}$ doxorubicin as indicated (DOX) and continued with or without $100 \mathrm{ng} / \mathrm{mL}$ paclitaxel (PTX). Cell survival was measured by MTT assay 2 days after PTX addition. cells are more sensitive to the cytotoxic effects of doxorubicin and undergo cell death by day 4 , whereas cytostatic doses of doxorubicin did not kill HCT116 arrested in $\mathrm{G}_{2}$ phase for at least 1 week. Growth arrest without cell death, which can be achieved in parental cells, cannot be achieved in $\mathrm{p} 21^{-/-}$cells, consequently cytoprotection against paclitaxel is lost.

In HCT116 cells, doxorubicin-pretreatment prevented cell death caused by other microtubule drugs including vincristine, Colcemid (depolymerizing agents), and epothilone A (like paclitaxel, a polymerizing agent) (Figure $4 a)$. In $\mathrm{p} 21^{-/-}$cells, all of these drugs were cytotoxic

b
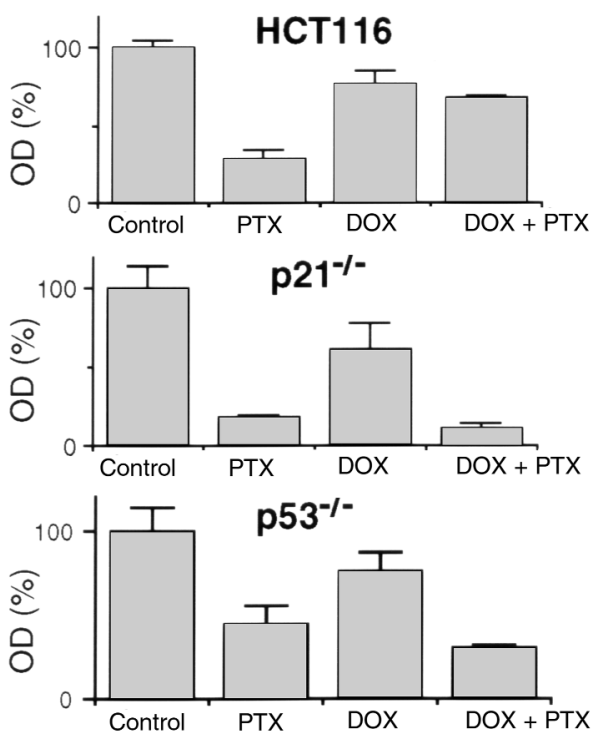
despite pretreatment with doxorubicin (Figure 4b). We next investigated FR901228, an experimental therapeutic drug and histone deacetylase inhibitor that does not interact with tubulin or microtubules but, in addition to $G_{1}$ and $G_{2}$ arrest, induces mitotic arrest in $20-25 \%$ of cells $(28,29)$. Given the ability to induce mitotic arrest in such large proportion of cells, FR901228 is the most appropriate control available with which to compare the microtubule-active drugs. Doxorubicin did not prevent cell death caused by FR901228 (Figure 4), indicating that its cytotoxicity may not require mitotic arrest and also that cytoprotection may be selective to microtubule-active drugs whose main mechanism of cytotoxicity is mitotic arrest. Furthermore, FR901228 -induced cytotoxicity was enhanced in cell pretreated with doxorubicin (Figure 4).

Reintroduction of $\mathrm{p} 21$ into $\mathrm{p} 21^{-/-}$cells results in high levels of p21 (Figure 5a). Cell-cycle analysis revealed that p21 arrested p21 $1^{-/}$cells at the $\mathrm{G}_{2}$ and $\mathrm{G}_{1}$ phases (Figure $5 \mathrm{~b}$ ) and partially abrogated paclitaxel-induced cytotoxicity (Figure 5c). Therefore, p21, but not doxorubicin, was able to diminish cell death induced by paclitaxel in the cells lacking endogenous p21.

Lack of cytoprotection in p53-deficient HCT116 cells. We next examined HCT116 cells lacking wt p53 gene $\left(\mathrm{p} 53^{-/-}\right)(19)$. P53 protein was undetectable in $\mathrm{p} 53^{-/-}$ cells (Figure 6a), and, as in $\mathrm{p}^{21^{-/}}$cells, doxorubicin could not induce p21 (Figure 6a). p53 $3^{-/-}$cells were more resistant to paclitaxel than $\mathrm{p}^{21^{-/} \text {cells (Figure }}$ $6 \mathrm{~b})$. Despite this difference in the basal sensitivity to paclitaxel, neither $\mathrm{p} 53^{-/-}$cells nor $\mathrm{p} 21^{-/-}$cells were protected by doxorubicin from paclitaxel-induced cytotoxicity (Figure 6b). Similar results were obtained with E6-expressing HCT116 cells with undetectable p53 protein (data not shown).

\section{Discussion}

One of the greatest challenges in cancer therapy is to develop treatment regimens with improved therapeutic indices by exploiting the disruption of checkpoint controls in tumor cells (30-34). As has been convincingly demonstrated previously $(8,19)$, the $\mathrm{G}_{2}$ arrest that follows DNA damage depends on p53 and p21, whereas cells lacking p53 or p21 enter mitosis (19). We exploited this difference in checkpoint fidelity, taking into account that microtubule-active drugs, such as paclitaxel or vinca alkaloids, can induce mitotic arrest only in cells that enter mitosis; and in turn, prolonged mitotic arrest causes cell death (22). We demonstrate that low doses of a DNA-damaging drug, doxorubicin, predominantly induces $\mathrm{G}_{2}$ arrest in HCT116 cells and thus protects against cytotoxicity induced by microtubule drugs. Paclitaxel-induced mitotic arrest is accompanied by protein hyperphosphorylation and is followed by cell death, whereas pretreatment with $100 \mathrm{ng} / \mathrm{mL}$ doxorubicin for 12-16 hours abrogates these events. Protection by doxorubicin from the cytotoxicity of other microtubuleactive drugs (epothilones A and B, vincristine) was also achieved. Thus, cells with intact checkpoints can be protected by pretreatment with a DNA-damaging agent, and the optimal dose is that which induces a sustained $\mathrm{G}_{2}$ arrest without cell death.

In agreement with previous results after radiation (19), both the $G_{1}$ and $G_{2}$ arrests induced by low doses of doxorubicin are p21 dependent, and, despite pretreatment with doxorubicin, $\mathrm{p} 21^{-/-}$cells died 2 days after treatment with microtubule-active drugs. Furthermore, overexpression of p21 alone using an Ad-p21 vector provided partial cytoprotection from paclitaxel. In addition, even though p53-deficient HCT116 cells were somewhat more resistant to paclitaxel than were either parental or p21-deficient cells, they were not protected by doxorubicin from paclitaxel cytotoxicity.

Cytoprotective effects of p21 against paclitaxelinduced cytotoxicity have been demonstrated previously (35-38). Those studies implied that cytoprotection was due to inhibition of Cdc2 kinase causing cell exit from mitosis. In our model, cytoprotection by DNA damage exploits different phenomena. First, induction of $\mathrm{p} 21$ by doxorubicin causes complete cytoprotection by preventing entry into mitosis. Second, although p21 is required for the doxorubicinmediated abrogation of paclitaxel cytotoxicity, p21 cannot substitute for doxorubicin. High p21 levels after Ad-p21 induced predominantly $\mathrm{G}_{1}$ arrest, whereas doxorubicin predominantly arrested HCT116 cells at $\mathrm{G}_{2}$. Thus, although p21 is required, doxorubicin may use additional mechanisms $(25,26)$ as well as p53-independent pathways. Therefore, doxorubicin-induced arrest is not equivalent to p21- or p53-induced arrest. Indeed, cytostatic doses of doxorubicin are more effective than p21 in providing cytoprotection against microtubule drugs. Finally, although cytoprotection by p 21 is biologically significant, cytoprotection by drugs could be potentially used in clinical practice. Doxorubicin, used in the present study, is protective over a narrow concentration range because of the toxicity at higher doses. However, it provides a model for protection of cells using their intact checkpoints, whereas less toxic drugs could be exploited to induce p53 and p21.

\section{Acknowledgments}

We thank B. Vogelstein and W.S. El-Deiry for cell lines and reagents.

\footnotetext{
1. Horwitz, S.B. 1992. Mechanism of action of taxol. Trends Pharmacol. Sci. 13:134-136.

2. Rowinsky, E.K., and Donehower, R.C. 1995. Paclitaxel (Taxol). N. Engl. J. Med. 332:1004-1014.

3. Kastan, M.B., Onyekwere, O., Sidransky, D., Vogelstein, B., and Craig, R.W. 1991. Participation of p53 protein in the cellular response to DNA damage. Cancer Res. 51:6304-6311.

4. El-Deiry, W.S., et al. 1993. WAF1, a potential mediator of p53 tumor suppression. Cell. 75:817-825.

5. Brugarolas, J., et al. 1995. Radiation-induced cell cycle arrest compromised by p21 deficiency. Nature. 377:552-557.

6. Deng, C., Zhang, P., Harper, J.W., Elledge, S.J., and Leder, P. 1995 Mice lacking p21CIP1/WAF1 undergo normal development, but are defective in G1 checkpoint control. Cell. 82:675-684.

7. Waldman, T., Kinzler, K.W., and Vogelstein, B. 1995. p21 is necessary
} 
for the p53-mediated G1 arrest in human cancer cells. Cancer Res. 55:5187-5190.

8. Waldman, T., Lengauer, C., Kinzler, K.W., and Vogelstein, B. 1996 Uncoupling of $\mathrm{S}$ phase and mitosis induced by anticancer agents in cells lacking p21. Nature. 381:643-644.

9. Fearon, E.R., and Vogelstein, B. 1990. A genetic model for colorectal tumorigenesis. Cell. 61:759-767.

10. Vogelstein, B., and Kinzler, K.W. 1992. p53 function and dysfunction. Cell. 70:523-526.

11. Levine, A.J. 1997. p53, the cellular gatekeeper for growth and division. Cell. 88:323-331.

12. Clarke, A.R., et al. 1993. Thymocyte apoptosis induced by p53dependent and independent pathway. Nature. 362:849-852.

13. Lowe, S.W., Ruley, H.E., Jacks, T., and Housman, D.E. 1993. p53dependent apoptosis modulates the cytotoxicity of anticancer agents. Cell. 74:957-967.

14. Bunz, F., et al. 1999. Disruption of p53 in human cancer cells alters the responses to therapeutic agents. J. Clin. Invest. 104:263-269.

15. Lowe, S.W., et al. 1994. p53 status and the efficacy of cancer therapy in vivo. Science. 266:807-810.

16. Lowe, S.W. 1995. Cancer therapy and p53. Curr. Opin. Oncol. 7:547-553.

17. O'Connor, P.M., et al. 1997. Characterization of the p53 tumor suppressor pathway in cell lines of the National Cancer Institute anticancer drug screen and correlations with growth-inhibitory potency of 123 anticancer agents. Cancer Res. 57:4285-4300.

18. Komarov, P.G., et al. 1999. A chemical inhibitor of p53 that protects mice from the side effects of cancer therapy. Science. 285:1733-1737.

19. Bunz, F., et al. 1998. Requirement for p53 and p21 to sustain G2 arrest after DNA damage. Science. 282:1497-1501.

20. Torres, K., and Horwitz, S.B. 1998. Mechanisms of Taxol-induced cell death are concentration dependent. Cancer Res. 58:3620-3626.

21. Jordan, M.A., and Wilson, L. 1998. Microtubules and actin filaments: dynamic targets for cancer chemotherapy. Curr. Opin. Cell Biol. 10:123-130.

22. Blagosklonny, M.V., and Fojo, T. 1999. Molecular effects of paclitaxel: myths and reality. Int. J. Cancer. 83:151-156.

23. Blagosklonny, M.V., Somasundaram, K., Wu, G.S., and El-Deiry, W.S 1997. Wild-type p53 is not sufficient for serum starvation-induced apoptosis in cancer cells but accelerates apoptosis in sensitive cells. Int. J. Oncol. 11:1165-1170.

24. Agarwal, M.L., Agarwal, A., Taylor, W.R., and Stark, G.R. 1995. p53 controls both the G2/M and the G1 cell-cycle checkpoints and mediates reversible growth arrest in human fibroblasts. Proc. Natl. Acad. Sci. USA. 92:8493-8497.

25. Hermeking, H., et al. 1997. 14-3-3 sigma is a p53-regulated inhibitor of G2/M progression. Mol. Cell. 1:3-11.

26. Wang, X.W., et al. 1999. GADD45 induction of a G2/M cell cycle checkpoint. Proc. Natl. Acad. Sci. USA. 96:3706-3711.

27. Blagosklonny, M.V., Iglesias, A., Zhan, Z., and Fojo, T. 1998. Like p53, the proliferation-associated protein p120 accumulates in human cancer cells following exposure to anticancer drugs. Biochem. Biophys. Res. Commun. 244:368-373.

28. Ueda, H., et al. 1994. FR901228, a novel antitumor bicyclic depsipeptide produced by Chromobacterium violaceum No. 968. Antitumor activities on experimental tumors in mice. J. Antibiot. (Tokyo). 47:315-323.

29. Nakajima, H., Kim, Y.B., Terano, H., Yoshida, M., and Horinouchi, S. 1998. FR901228, a potent antitumor antibiotic, is a novel histone deacetylase inhibitor. Exp. Cell Res. 241:126-133.

30. Fisher, D.E. 1994. Apoptosis in cancer therapy: crossing the threshold. Cell. 78:539-542.

31. Kastan, M.B., Canman, C.E., and Leonard, C.J. 1995. P53, cell cycle control and apoptosis: implications for cancer. Cancer Metastasis Rev. 14:3-15

32. Kaelin, W.G.J. 1999. Choosing anticancer drug targets in the postgenomic era. J. Clin. Invest. 104:1503-1506.

33. Shapiro, G.I., and Harper, J.W. 1999. Anticancer drug targets: cell cycle and checkpoint control. J. Clin. Invest. 104:1645-1653.

34. Sellers, W.R., and Fisher, D.E. 1999. Apoptosis and cancer drug targeting. J. Clin. Invest. 104:1655-1661.

35. Yu, D.H., et al. 1998. Overexpression of ErbB2 blocks taxol-induced apoptosis by upregulation of p21(Cip), which inhibits p34(Cdc2) kinase. Mol. Cell. 2:581-591.

36. Barboule, N., Chadebech, P., Baldin, V., Vidal, S., and Valette, A. 1997. Involvement of $\mathrm{p} 21$ in mitotic exit after paclitaxel treatment in MCF7 breast adenocarcinoma cell lines. Oncogene. 15:2867-2875.

37. Li, W., Fan, J., Banerjee, D., and Bertino, J.R. 1999. Overexpression of p21(waf1) decreases G2-M arrest and apoptosis induced by paclitaxel in human sarcoma cells lacking both p53 and functional Rb protein. Mol. Pharmacol. 55:1088-1093.

38. Stewart, Z.A., Mays, D., and Pietenpol, J.A. 1999. Defective G1-S cell cycle checkpoint function sensitizes cells to microtubule inhibitorinduced apoptosis. Cancer Res. 59:3831-3837. 